Efficiency of seismic isolation on industrial plants - case study of a gas tank Peer-reviewed author version

Henriques, Jose; Morelli, Francesco; VANDOREN, Bram; Salvatore, Walter \& DEGEE, Herve (2016) Efficiency of seismic isolation on industrial plants - case study of a gas tank. In: Proceedings of the 7th European Congress on Computational Methods in Applied Sciences and Engineering,p. 5896-5911.

DOI: $10.7712 / 100016.2227 .10247$

Handle: http://hdl.handle.net/1942/23662 


\title{
EFFICIENCY OF SEISMIC ISOLATION ON INDUSTRIAL PLANTS - CASE STUDY OF A GAS TANK
}

\author{
J. Henriques ${ }^{1}$, F. Morelli ${ }^{2}$, B. Vandoren ${ }^{1}$, W. Salvatore ${ }^{2}$ and H. Degée ${ }^{1}$ \\ ${ }^{1}$ Construction Engineering Research Group, Faculteit IIW, Universiteit Hasselt \\ e-mail: jose.gouveiahenriques@uhasselt.be; herve.degee@uhasselt.be \\ ${ }^{2}$ Dipartimento di Ingegneria Civile ed Industriale, Universitá di Pisa \\ email: francesco.morelli@dic.unipi.it; walter@ing.unipi.it
}

Keywords: Industrial Plants, Seismic Protection, Ground Motion, Time-History Analysis, Numerical Simulation.

\begin{abstract}
Recent earthquakes such as the one in Fukushima in Japan in 2011 highlighted the need of providing adequate protection to industrial installations. To answer this need, the ongoing RFCS research project PROINDUSTRY is addressing the question of the development of innovative seismic protection systems, both for the design of new industrial plants and for the retrofit of existing ones. This paper presents a specific aspect of the ongoing investigations within the referred project, namely a case study considering a Gas Tank. The protection systems under development contemplate both seismic isolation and energy dissipation techniques. For the presented case study, the base isolation system under development was finally chosen to improve the seismic performance of the Tank structure. In order to characterize the behavior of the Gas Tank structure, several numerical simulations were performed comprising modal analyses, push-over analyses and time-history nonlinear analyses. For the time-history nonlinear analysis ground motions were generated on the basis of available information on ground motion histories from national, European and Mediterranean Strong Motion Data-bases. Finally, the efficiency of the base isolation used in the Gas Tank structure is investigated by comparing the results of the time-history nonlinear analysis on the protected and the non-protected structure.
\end{abstract}




\section{INTRODUCTION}

Recent earthquakes such as the one in Fukushima in Japan in 2011 highlighted the need of providing adequate protection to industrial installations storing a large amount of hazardous material. In the event of an earthquake, and following accidental scenario, the consequences may be severe for the neighborhood population, for the economy and for the environment [1]. In particular process plants, like process units, storage units and piping systems are characterized by high level of seismic risk [2]. The consequences of an earthquake may be the total collapse (Fig. 1-a) or a partial damage (Fig. 1-b) of the industrial unit. Consequently, providing adequate seismic protection to industrial installations is imperative to this construction sector. In order to answer to this problematic, the on-going RFCS research project PROINDUSTRY [3] is addressing the question by developing innovative seismic protection systems, both for the design of new industrial plants and for the retrofit of existing ones. The seismic protection systems considered in the project programme are the Base Isolation (IS) and the Energy Dissipation (EDS) types. Emphasis is given to the self-centering capability of these systems, since it is an essential feature that allows the industrial facility not to discontinue its operations even after a strong earthquake and that makes eventual repair work easier. The work programme considers experimental tests on the developed devices, including application in substructures, and numerical modelling of real industrial structures used as study cases to investigate and calibrate the seismic protection systems developed. The cases studies of real industrial buildings consider process and storage units which the superstructure is made of steel [4].

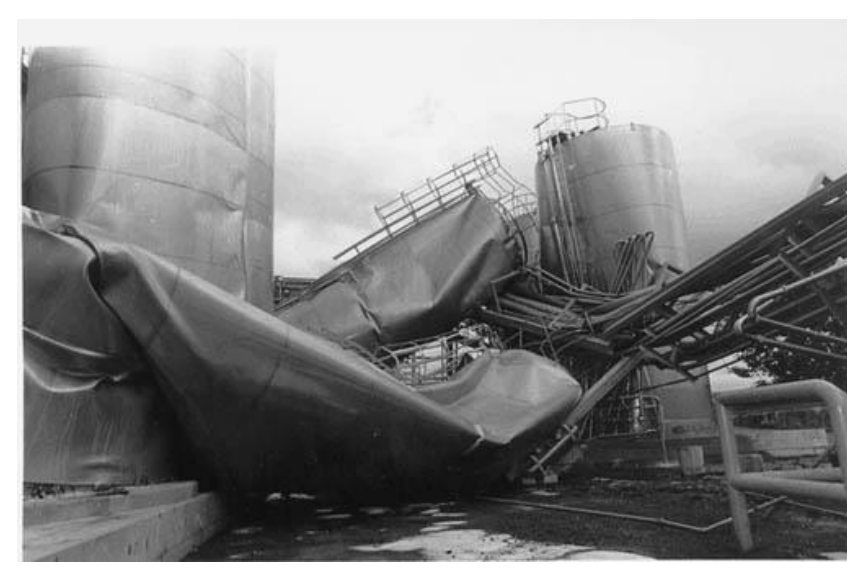

a) Tank collapse (Edgecumbe Earthquake, New Zeeland)

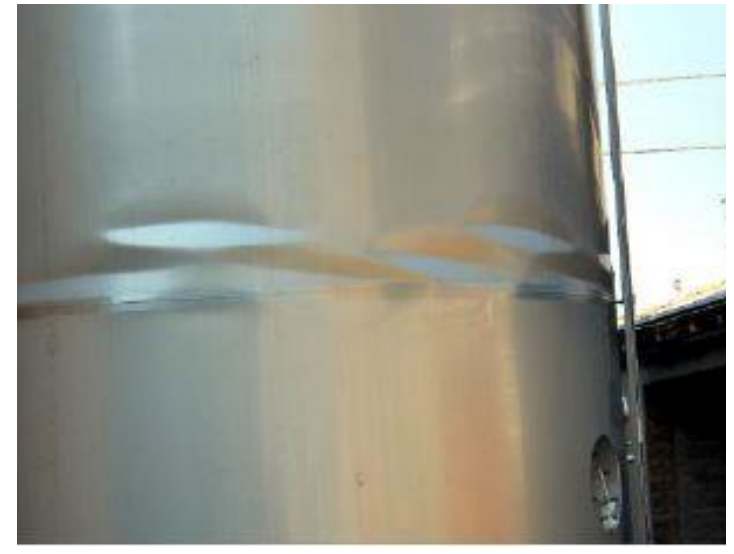

b) Local shell buckling (Emilia earthquake, Italy)

Figure 1: Earthquake impact on industrial units

This paper presents a specific aspect of the on-going investigations within the referred project, namely a case study considering a gas tank. For this structure, a base isolation system was chosen to improve its seismic performance. In order to characterize the behavior of the Gas Tank structure, several numerical simulations were performed comprising modal, push-over and time-history nonlinear analysis. For the latter, the Ground Motions generated within the project tasks have been used. The calibration of the foreseen base isolation system is under investigation and the preliminary results of the time-history nonlinear analysis on the protected structure are compared with the response of the non-protected structure. 


\section{SEISMIC PROTECTION OF INDUSTRIAL PLANTS}

\subsection{General}

In the case of seismic event, the prevention of the collapse of buildings may rely in two strategies: i) capacity design; ii) seismic isolation and/or energy dissipation (seismic protection). The PROINDUSTRY research project is focus on the latter. Accordingly, base isolation systems and energy dissipation systems are under development for the retrofit intervention of existing industrial structures or the design of new ones. In the case study presented in this paper, the base isolation system has been selected to improve the seismic performance of the structure under analysis. Herein, only a brief description of the base isolation system is given. More detailed information on the base isolation and on the dissipation devices subject of the PROINDUSTRY investigations may be found in [4].

The aim of the base isolation system is to mitigate the impact of seismic action on the structure by decoupling the structure from the shaking ground. The principle of seismic base isolation is to increase the fundamental period of the structure and modify the mode shape leading to smaller rigid mass displacements, and consequently reduce the loads due to inertia effects. An isolator shall provide a combination of vertical-load carrying capability with one or more of the following functions: i) lateral flexibility; ii) energy dissipation; iii) re-centering capability. The base isolation system implemented in the numerical simulation is the Curved Surface Slider (CSS) which may present different versions: single CSS, double CSS and triple CSS. Within the project, an innovative version of this device is under development [4].

\subsection{Base Isolation System: Curved Surface Slider}

The simple version of the CSS was proposed in [5] and consisted in a single curved surface slider (Figure 2-a). In concept, the single surface slider is derived from the regular spherical bearing in which the flat surface accommodating the translation movements is substituted by a curved concave surface (Figure 2-b). The spherical sliding isolators are consisting of three main steel parts with inner sliding surfaces. The shape of the internal part is always spherical and allowing rotation and horizontal sliding displacements. The device transmits vertical loads, provides horizontal flexibility and dissipates energy simultaneously. The concave surface introduces the re-centering capability into the isolator: the slide moves up the concave surface (under the seismic excitation), increasing the potential energy, inducing in the bearing a restoring force, as the building should return to its stable equilibrium point. The theoretical behavior of the device is characterized by hysteretic bilinear relationship between horizontal force - horizontal displacement (Figure 3). From the single CSS, a double and triple CSS were developed (Figure 2-c). These modified versions of the single CSS improve its capacity to accommodate substantially larger displacements and allows the adaptation of device to the earthquake intensity.
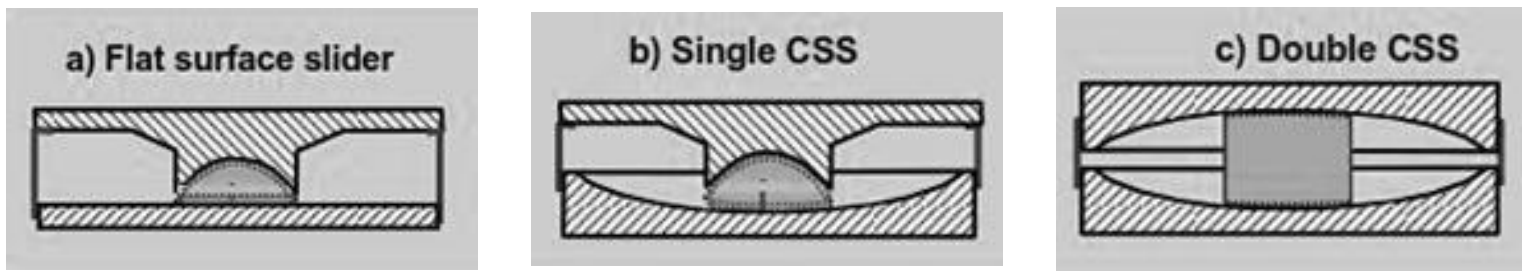

Figure 2: Flat and curved surface sliding isolators [4] 


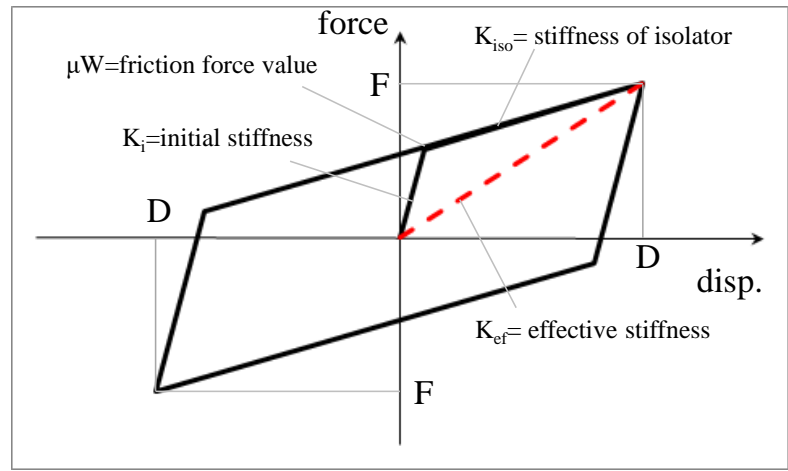

Figure 3: Hysteretic force - displacement relationship of the CSS [4]

\section{CASE STUDY: GAS TANK}

\subsection{Geometric and mechanical properties}

The present case study consists in a Gasometer which is used to store Gas AFO (Figure 4) and was constructed by Ilva s. p. a. in the early eighties. The gas tank is a steel cylinder where the walls are made with curved steel plates reinforced with circular steel rings (UNP 100) and with vertical steel columns (IPB 180). The roof is composed by a steel structure using a steel circular grid made of IPE, L and UNP steel profiles and steel plates. The tank works with a pistonfender system and a rubber sealing system which allows the variation of the sealed volume. In Table 1 the main geometric characteristics are summarized and in Table 2 are given the material properties of the main structural components. The self-weight of the different structural components is given in Table 3. Finally, the working pressure in this gas tank is $400 \mathrm{mmH} 2 \mathrm{O}$, and the volume between the roof and the sealed reservoir is full of air at atmospheric pressure. Detailed information on the tank properties is given in [4].

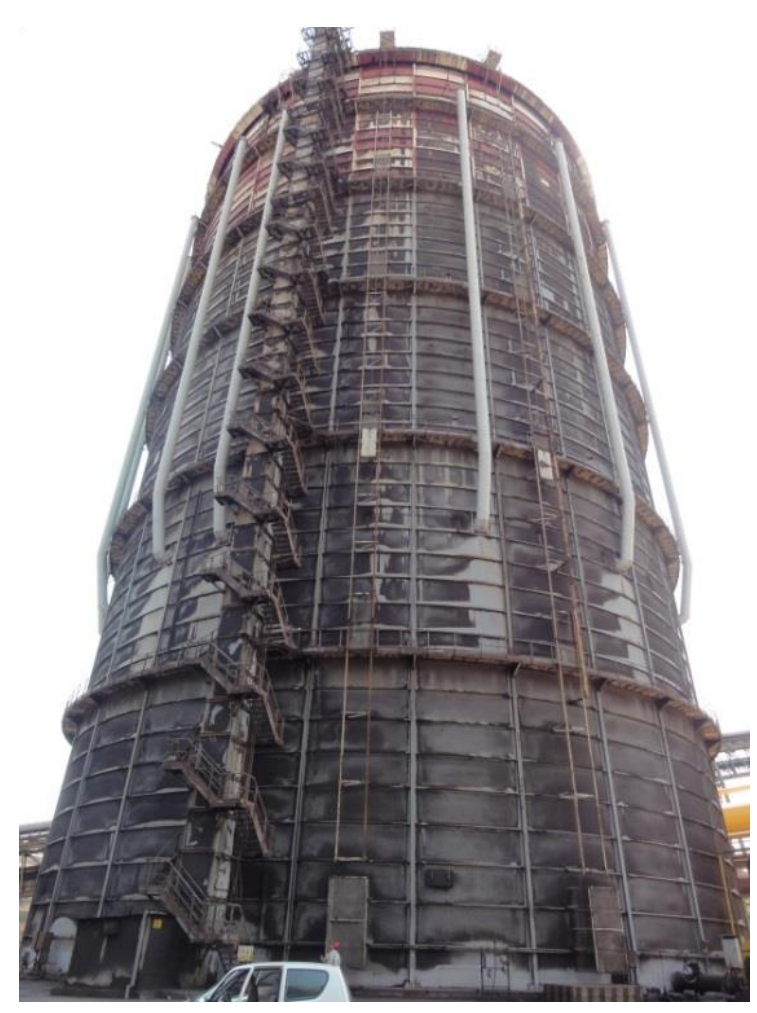

Figure 4: Gasometer
Table 1: Main Geometric Properties

\begin{tabular}{lc}
\hline Height & $70 \mathrm{~m}$ \\
Diameter & $44 \mathrm{~m}$ \\
Volume & $75000 \mathrm{~m}^{3}$ \\
Wall Shell Thickness & $5 \mathrm{~mm}$ \\
Roff Shell Thickness & $3 \mathrm{~mm}$ \\
Columns & IPB180 \\
Ring Stiffeners & UNP 100 \\
\hline
\end{tabular}

Table 2: Material Properties

\begin{tabular}{lc}
\hline Wall Shell & S275 JR \\
Roof Shell & S275 JR \\
Profiles & S235JR \\
\hline
\end{tabular}

Table 3: Structural Mass

\begin{tabular}{lc}
\hline Cylinder & 519ton \\
Roof & 153ton \\
Piston & 712ton \\
Auxiliary Structure & 43ton \\
\hline
\end{tabular}




\subsection{Finite element model}

The finite element (FE) numerical model developed considered some simplifications, as only the main structural components of the tank were modeled. These parts are: i) wall shell; ii) columns; iii) wall stiffening rings; iv) roof shell; v) roof structure. In Figure 5 is illustrated the FE model developed. According to the parts modeled, the following types of finite elements were used:

- Wall shell and roof shell: the element used is the S4R. This is a 4-node doubly curved thin or thick shell, reduced integration hourglass control, finite membrane strains. Five integration points through thickness.

- Columns, stiffening rings and roof structure: the element used is B31. This is a 2-node linear beam in space.

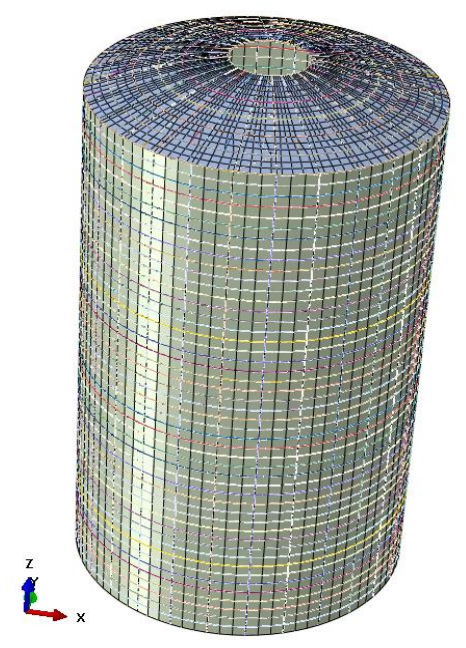

Figure 5: FE model developed

In order to consider the total mass of the tank, as the non-structural elements were neglected in the modelling, additional masses were introduced as non-structural masses. In Table 4 are described the additional masses considered. The total mass of the tank model, including structural and non-structural elements, is 1427 ton. The connections between the different structural members have been considered continuous, even in the case of the wall shell-column. These two members are connected using rivets along the total height of the columns, as depicted in Figure 6. In what concerns to the supports, connection to the ground, the column base were modeled as pinned connections. For the material mechanical behavior, an elasto-plastic with hardening constitutive law was used. Finally, it should be noticed the following:

- In the non-linear analyses, both material and geometrical nonlinearities are considered.

- As the working pressure $\left(400 \mathrm{mmH}_{2} \mathrm{O} \approx 0,039 \mathrm{~atm} \approx 3,92 \mathrm{kPa}\right)$ is relatively low; the mass of the gas was neglected.

- No geometrical imperfections and residual stresses were considered (analysis on perfect structure). 
Table 4: List of non-structural masses considered in the FE model

\begin{tabular}{|c|c|c|}
\hline Member & Additional Mass [ton] & Comments \\
\hline & 0.25 & $\begin{array}{c}\text { Mass of the non-structural } \\
\text { elements distributed along } \\
\text { the total height of the col- } \\
\text { umns. }\end{array}$ \\
\hline Columns & 713.0 & $\begin{array}{l}\text { Piston mass applied at high- } \\
\text { est possible position. The } \\
\text { mass is distributed amongst } \\
\text { all columns and along } \approx 6 \mathrm{~m} \\
\text { of the column length so that } \\
\text { the resultant is at the highest } \\
\text { working position. }\end{array}$ \\
\hline Roof Structure & 2.52 & $\begin{array}{l}\text { Additional mass due to non- } \\
\text { structural elements and dis- } \\
\text { tributed along the total } \\
\text { length of the roof structure } \\
\text { members. }\end{array}$ \\
\hline
\end{tabular}

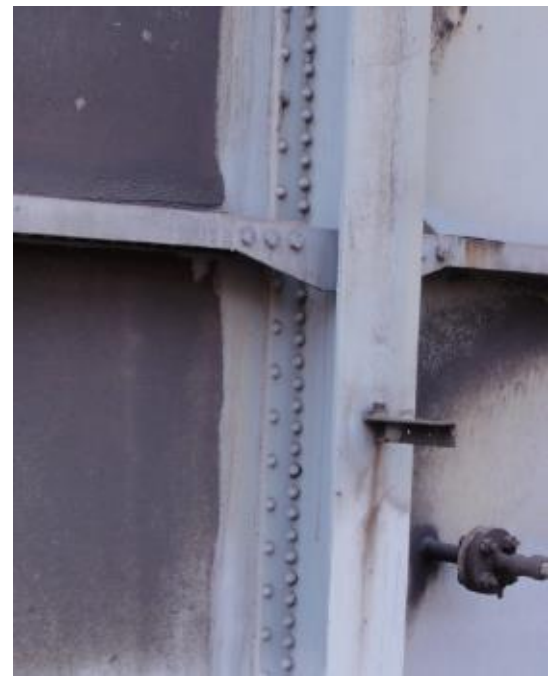

a) Connection detail

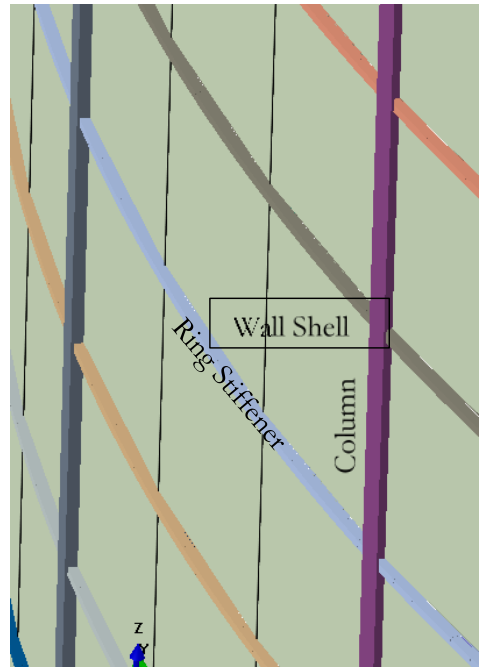

b) FE model detail

Figure 6: Connection between Column and Wall 


\subsection{FE model failure criteria}

In order to identify a possible failure of the structure during the analysis, the failure criteria in Table 5 have been specified.

Table 5: List of failure criteria

\begin{tabular}{cc}
\hline Criterion & Description \\
\hline $1-$ Limit of plastic strains & $\varepsilon_{\mathrm{u}}=0.2$ \\
$2-$ Global or local instability & $\begin{array}{c}\text { Global loss of stability of the structure or lo- } \\
\text { cal instability of parts of the structure. }\end{array}$ \\
tion & $\begin{array}{c}\text { Exceedance of the resistance of the column } \\
\text { bases connection to uplift loads. }\end{array}$ \\
\hline
\end{tabular}

In order to avoid the complexities related to the modelling of the column bases connection, the third criterion is verified in the post-processing of the numerical results, comparing the uplift forces with the column base resistance. The resistance of the column bases was determined according to the design rules given in [6] and [7]. For the present case study, the resistance is $315 \mathrm{kN}$.

In what concerns the wall shell of the gas tank, though at first one may regarded the tank structure as a shell structure reinforced by the columns (usually called stringers in shell structures), their resistance to buckling is barely inexistent. The resistance of the shell was estimated according to [8] and [9]. The tank structure stability is then guaranteed by a "classic" structure composed of columns and beams, being the main function of the wall and roof shells the resistance to the internal and external pressures, and consequently distribute these pressures to the main structural members. The second function of the wall shell is to contribute to the global lateral stiffness of the structure.

\section{SEISMIC PERFOMANCE OF NON-ISOLATED STRUCTURE}

\subsection{General}

In a first stage, the performance of the original gas tank structure to seismic actions was evaluated. Several numerical simulations were conducted in order to characterize the structure response to dynamic actions, developing inertia forces on the structure, and to evaluate the seismic performance of the non-isolated structure. The performed simulations considered the following types:

- Modal Analysis

- Push-over Analysis

- Time-History Nonlinear Analysis $\rightarrow$ Incremental Dynamic Analysis

For the Time-History Nonlinear Analysis, and Incremental Dynamic Analysis, and within the scope of the PROINDUSTRY project [4], two sets of 11 Ground Motions (GM) have been generated on the basis of available information on ground motion histories from national, European and Mediterranean Strong Motion Data-bases. One set is representative of areas with low-medium seismicity and another set is representative of areas with high seismicity. ground motions were 


\subsection{Modal analysis}

In order to obtain the natural vibration modes, a modal analysis was executed. The procedure used consists in the Lanczos method. The range of frequencies in the calculation was limited to $20 \mathrm{~Hz}$. Within the range of frequencies between $0 \mathrm{~Hz}$ and $20 \mathrm{~Hz}$, only two global modes were observed and these correspond to the same mode though, for each orthogonal direction. Many local modes (percentage of mass participation is almost zero) were obtained. The first natural frequency is $2,64 \mathrm{~Hz}$ with a total mass participation of $88,65 \%$ in the main direction and nearly $0 \%$ in the other orthogonal direction. Figure $7-a)$ presents the shape of the $1^{\text {st }}$ natural frequency. The local deformation at approximately $2 / 3$ of the height is due to the consideration of the piston mass at this position (highest position possible). Figure 7-b) presents the first mode obtained in the calculations which represents a local mode.

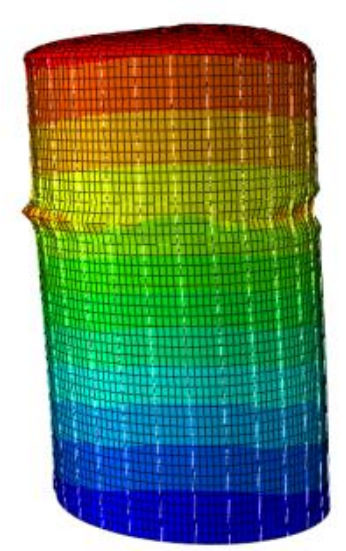

a) $1^{\text {st }}$ global mode

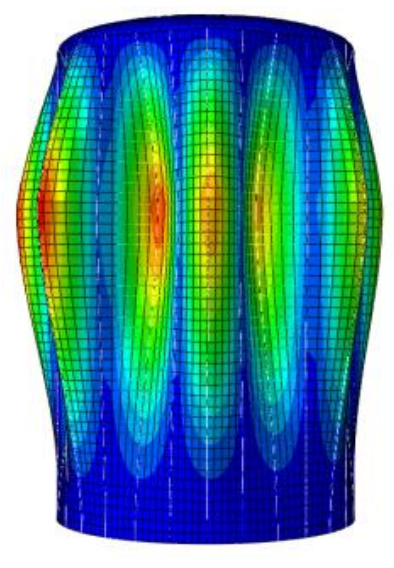

b) $1^{\text {st }}$ local mode

Figure 7: Natural vibration modes of the gas tank structure

\subsection{Push-over analysis}

The push-over analysis consisted in applying a horizontal force at the center of mass of the tank. Given the magnitude of the piston mass, the position considered was the highest working height of the piston, approximately $2 / 3$ of the gas tank height (see Figure 8 ). The load was applied directly to the columns, as these members are the vertical support of the piston. The load was distributed within a length which approximates the length of the piston structure inside the tank. The load was increased until one of the following failure criteria was achieved: i) plastic limit strain attained; ii) local or global instability detected by the numerical calculation. In this analysis the column bases connections resistance was disregarded.

In Figure 9 is presented the force-displacement curve obtained from the push-over analysis. The force corresponds to the base shear and the displacement is the displacement measure at the top of the gas tank structure (at the top of the columns). The maximum load is identified by a peak in the force-displacement curve. A sudden loss of resistance after this peak load is observed which is due to loss of stability of the gas tank structure. Then, there is an increase of resistance after equilibrium is recovered. The ultimate strain is attained in the tank structure members later for a significant lateral displacement. 


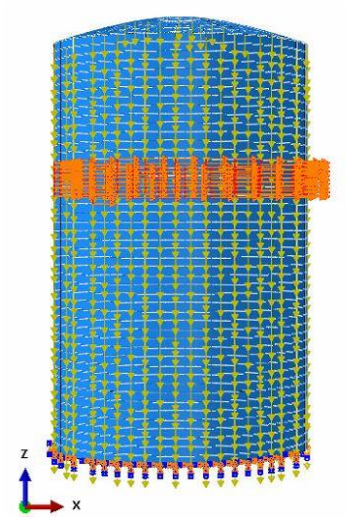

Figure 8: Location of the loading in the push-over analysis

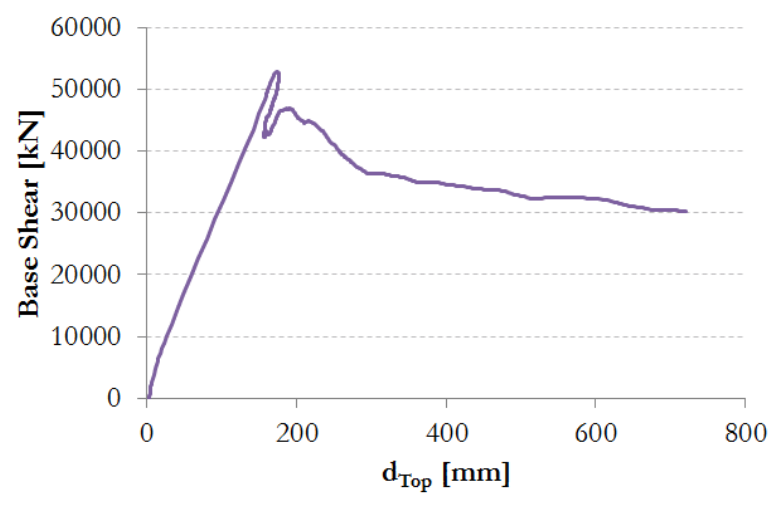

Figure 9: Force-displacement curve obtained from the pushover analysis

\subsection{Incremental dynamic analysis}

The nonlinear time-history analysis, basis of the incremental dynamic analysis (IDA), were performed using the general nonlinear dynamic analysis available using implicit time integration to calculate the transient dynamic or quasi-static response of a system.

The procedure used consisted in imposing base acceleration at the support nodes of the gas tanks structures. The base acceleration applied represent the ground motions generated within the project and referred above. These ground-motions are characterized by a time-history acceleration for each orthogonal direction (X, Y and Z). In the performed calculations, the ground motions (base accelerations) for each orthogonal direction were applied simultaneously. Two sets of ground motions were considered; one representative of low-medium seismicity areas, and one representative of high seismicity areas. In Table 6 are listed the spectral accelerations and the corresponding scale factors considered in IDA analyses.

Table 6: List of spectral accelerations used in the IDA

\begin{tabular}{cccc|cccc}
\hline & \multicolumn{3}{c|}{ Low Seismicity Areas } & \multicolumn{4}{c}{ High Seismicity Areas } \\
Pvr & Tr & ag & S. F. & Pvr & Tr & ag & S. F. \\
$\%$ & Yrs & g & $\backslash$ & $\%$ & Yrs & g & $\backslash$ \\
\hline 4 & 2475 & 0.199 & 2.78 & 4 & 2475 & 0.512 & 1.43 \\
5 & 1950 & 0.1854 & 2.592 & 5 & 1950 & 0.4687 & 1.307 \\
10 & 949 & 0.1501 & 2.098 & 10 & 949 & 0.3586 & 1.000 \\
22 & 402 & 0.1140 & 1.593 & 22 & 402 & 0.2502 & 0.698 \\
30 & 280 & 0.1016 & 1.420 & 30 & 280 & 0.2122 & 0.592 \\
39 & 202 & 0.0916 & 1.280 & 39 & 202 & 0.1829 & 0.510 \\
50 & 144 & 0.0812 & 1.135 & 50 & 144 & 0.1552 & 0.433 \\
63 & 101 & 0.0715 & 1.0 & 63 & 101 & 0.1292 & 0.360 \\
\hline
\end{tabular}

In all executed calculations, the time-history was completed. Consequently, the two first failure criteria specified in Table 5 were not violated. In order to evaluate the global deformation of the structure, the relative displacement of the roof was computed. In Figure 10 are presented the results for both sets of GMs, High and Low-Medium seismicity areas, and for one of the orthogonal directions in the ground plane. The values represent the maximum values obtained through the time-history simulation. For almost all cases the structure is on the linear range. 
Local yielding is observed however; this is not reflected on the global response. The maximum value is $150 \mathrm{~mm}$. Taken into account the height of the gas tank and that in the vicinity, at least $2 \mathrm{~m}$ separate this gas tank from other structure, the values is barely insignificant.

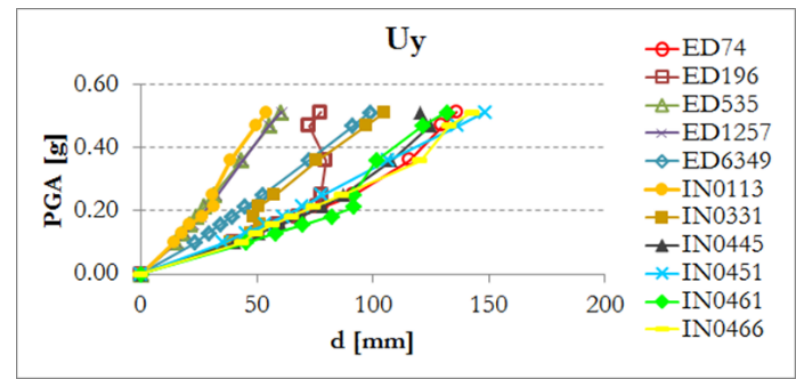

a) High seismicity areas

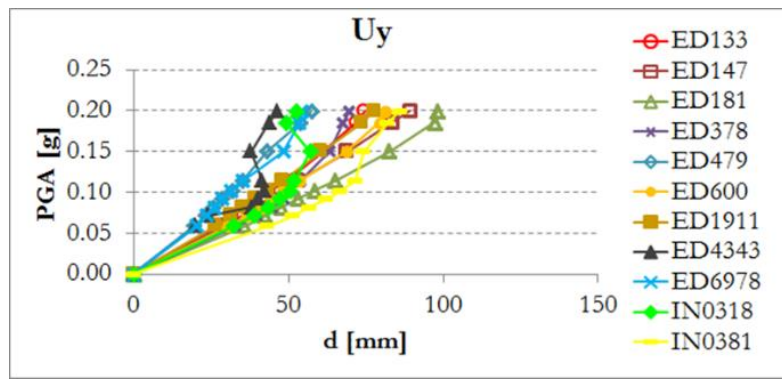

b) Low seismicity areas

Figure 10: Gas tank roof relative displacements result of IDA calculations on non-isolated structure

In Figure 11 is plotted the parameter which expresses the plastic strains, the equivalent plastic strain (PEEQ). These plastic deformations are located in the members, mainly in columns and ring stiffeners, in the region of the piston mass and consequently, the region were the inertia forces are greater. In Figure 11 only the maximum values are shown, for each time-history simulation of the IDA analysis. Since for Low-Medium Seismicity GMs these are barely inexistent, only the values for the High Seismicity GMs are presented. In the chart is included the limit strain considered in the numerical models (0.2). It can be observed that not only this limit was not exceeded, but the maximum equivalent plastic strain is approximately half of this limit. Up to a scale factor of 1.0, an almost linear relation between the peak ground acceleration characterizing the GMs and this parameter is obtained. For higher scale factors, for some cases this linearity is lost. This may be due to the damping effects when the plasticity becomes higher. However, in general this is not significantly reflected in the global response, as discussed above.

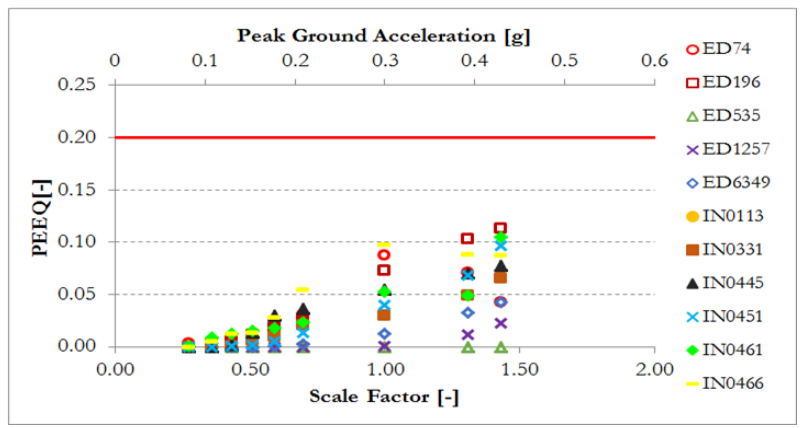

Figure 11: Maximum PEEQ result of IDA calculations on non-isolated structure (only High Seismicity areas GMs)

In order to verify the third failure criterion, the uplift forces on the column bases and the respective resistance were compared in Figure 12. These forces are due to the tank overturning and the vertical component of the seismic action. It can be seen that this is clearly a critical point of the structure. Only for few cases, amongst all GMs representing both seismicity's areas, and for the lowest scale factors, this resistance was not exceeded. In the case of the High Seismicity areas, the maximum values are considerably high, approximately 10 times greater, and almost impossible to overcome with improvement of the connection and therefore, seismic protection is required. 


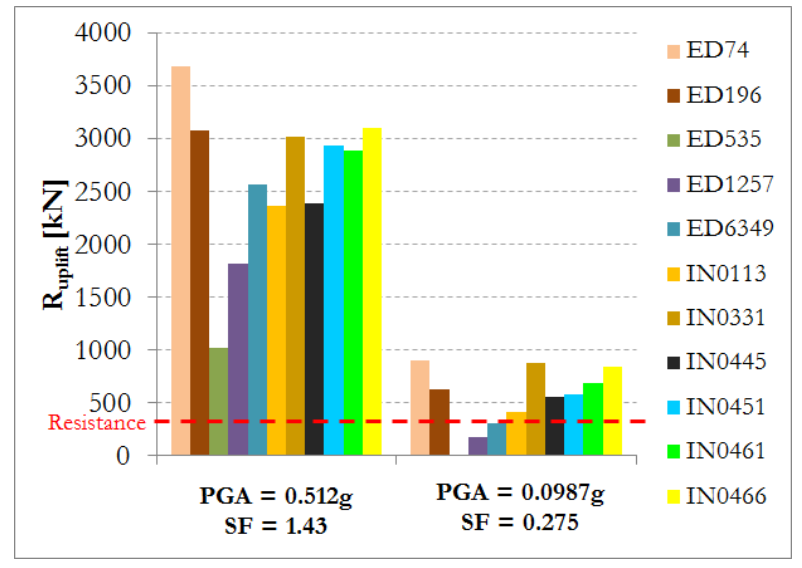

a) High seismicity areas

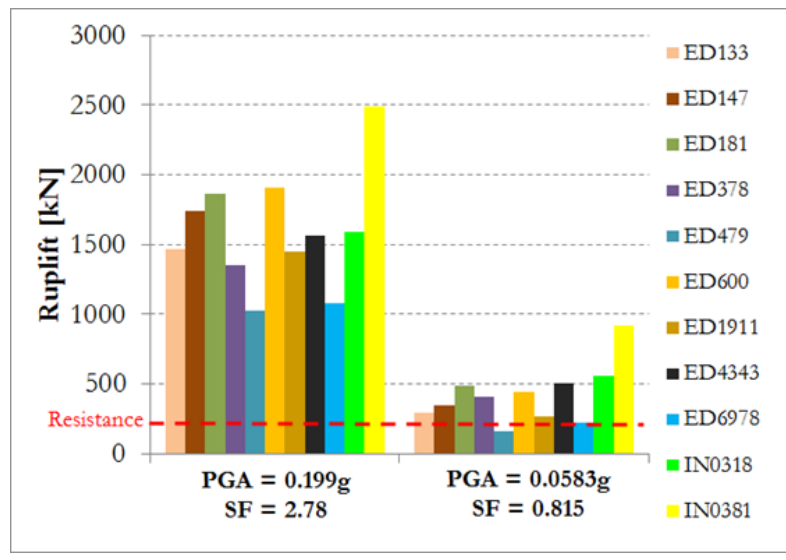

b) Low seismicity areas

Figure 12: Column bases uplift forces results of IDA calculations on the non-isolated structure

\section{EFFICIENCY OF THE SEISMIC PROTECTION SYSTEM: BASE ISOLATION SYSTEM}

\subsection{Model of the base isolation system}

For the base isolation system of the gas tank structure 28 units (isolators), one under each column, are foreseen. Note, that this should be placed in the same vertical position of the columns, not directly under the columns, but between a "Support" slab and the foundation (isolation interface), as illustrated in Figure 13. The incorporation of the isolators on the FE model consisted in a system that combines a spring element and an elastio-plastic element (or friction element) working in parallel. The spring element has a pure elastic linear behavior which represents the isolator stiffness to slip (dynamic friction). The friction element, incorporates the friction force (static friction) developed between the slider and the concave surfaces. The friction force is proportional to the superstructure mass $(\mathrm{M})$. It is usually assumed that the behavior of this element is rigid until the static friction is exceeded. Then, free deformation of this element is considered.

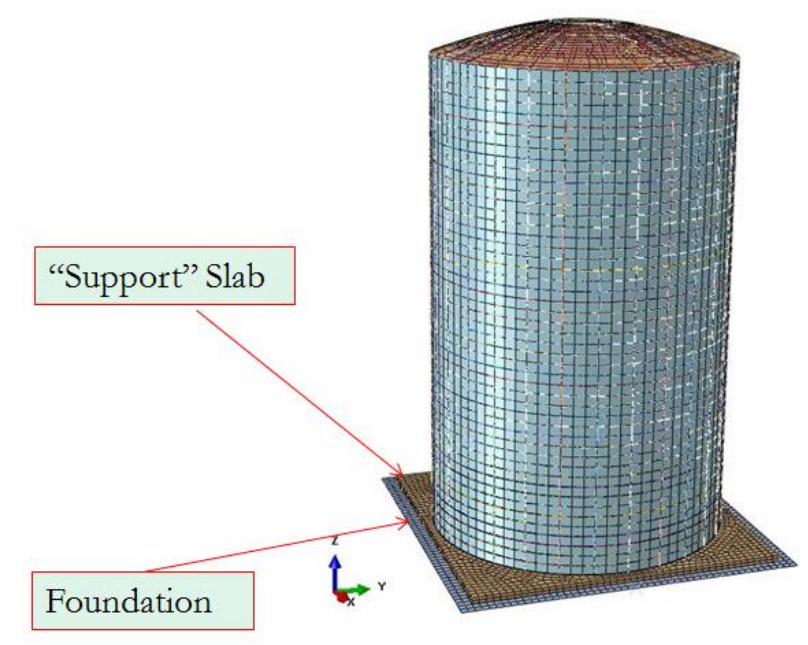

Figure 13: FE model of the base isolated gas tank structure 
To model the behavior of the isolation system, the following parameters are determined:

- The total weight (W) and mass (M) of the superstructure and of the "Support" slab above the isolation system.

- The friction coefficient $(\mu)$ between the slider and the concave surfaces.

- The fundamental period of the device. This values are usually between 3,5s and $4 \mathrm{~s}(\mathrm{~T})$.

- The stiffness of the Isolator which may be approximated by the following equation:

$$
k_{\text {isol }}=M \frac{4 \pi^{2}}{T^{2}}
$$

In Table 7 are presented the values of the parameters described above and assumed in the present case study. In Figure 14 is illustrated the force-displacement response of the isolation system.

Table 7: Properties of the base isolation system of gas tank structure

\begin{tabular}{ccccc}
\hline $\mathrm{M}$ & $\mathrm{W}$ & $\mu$ & $\mathrm{T}$ & $\mathrm{K}_{\text {iso,system }}$ \\
{$[$ ton $]$} & {$[\mathrm{kN}]$} & {$[-]$} & {$[\mathrm{s}]$} & {$[\mathrm{kN} / \mathrm{m}]$} \\
\hline 1581.1 & 15495.3 & 0.3 & 3.5 & 5095.6 \\
\hline
\end{tabular}

The determination of the properties of each isolator unit is obtained through "decomposition" of the equivalent isolation system properties described above. Remember, that in this case 28 individual isolators are considered. Given the symmetry of the structure, these 28 isolators have equal properties. Thus, the equivalent isolation system reproduces the behavior of 28 parallel isolators and accordingly the properties of each isolator unit are obtained: the elastic spring stiffness and friction element maximum force are divided by 28. In Figure 15, the properties of these two elements representing an isolator unit are shown.

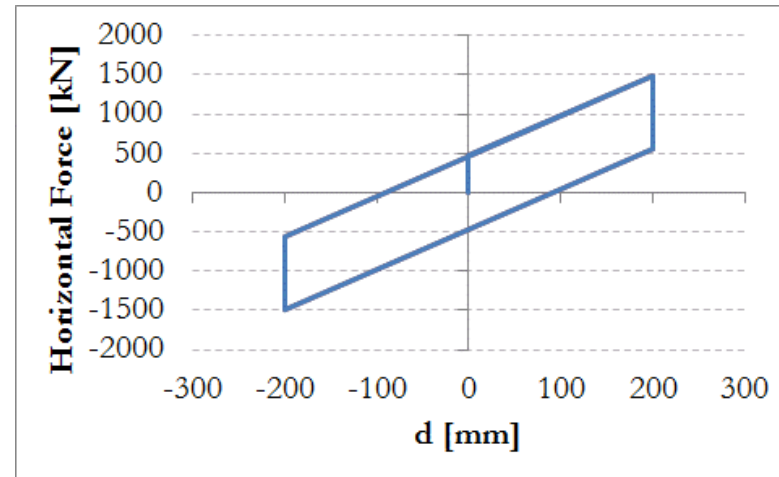

Figure 14: Force-displacement behavior of the base isolation system

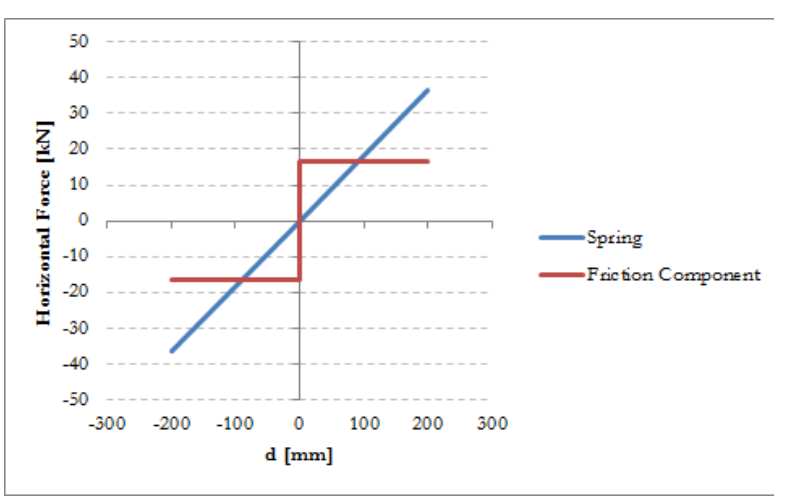

Figure 15: Behavior of the spring and friction element representing an isolator

\subsection{Impact on the structure response}

The purpose of the base isolation system is to reduce the horizontal (soil plane) base displacement of the superstructure. This is achieved through the seismic energy dissipated by the isolation system. At this stage, the isolators properties are in a process of calibration and therefore, only the time-history nonlinear analysis using the GMs, representing the high seismicity areas, were used. Furthermore, the simulations only considered the scale factor equal 1. In Figure 16 is shown the time-history tank roof relative displacement for one of the orthogonal direction on 
the base (ground) plane for GM ED74. The chart includes the results for both cases, non-isolated and isolated structure. The impact of the base isolation system is evident. The tank roof relative displacement on the isolated structure is $26 \%$ of the value obtained in the non-isolated structure. In Figure 17 are presented the maximum tank roof relative displacement, for one of the orthogonal directions (ground plane) achieved during the time-history nonlinear simulation. The chart includes all GMs representative of the high seismicity areas. The reduction on the gas tank roof relative displacement is a constant for all GMs. The results of the different GMs show that the most demanding GM for the non-isolated structure do not correspond to those for the isolated structure. This is expected as the isolated structure has a different response due to the modification on the fundamental period, which corresponds to that of the isolation system.

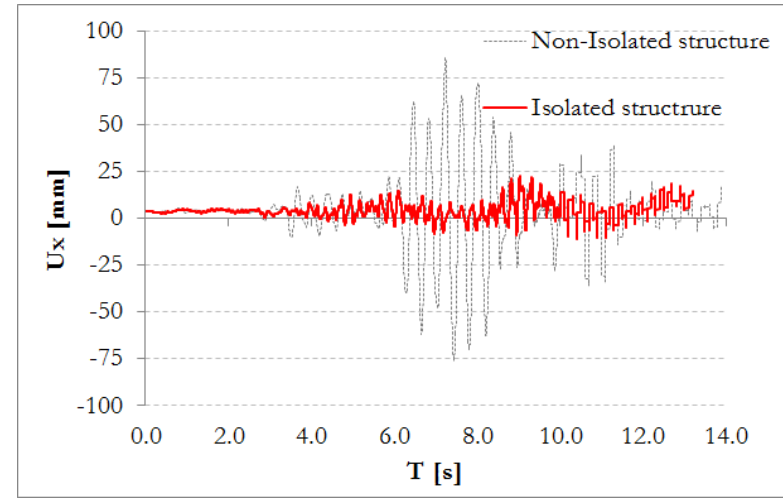

Figure 16: Time-history gas tank roof relative displacements comparing non-isolated and isolated structure

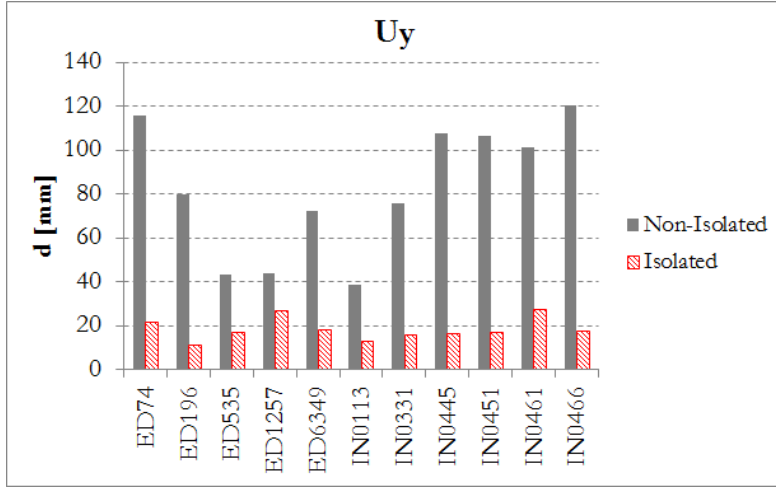

Figure 17: Maximum gas tank roof relative displacements comparing non-isolated and isolated structure (all GMs)

In Figure 18 are presented the results of the uplift forces on the columns. Remember that, according to the simulations on the non-isolated structure, column bases resistance to uplift forces are the critical parts of the present structure. A comparison with the results of the simulations on the non-isolated structure and the theoretical resistance of the column bases to uplift forces is included. Again, it is evident the impact of the base isolation system. It possible to see that for the isolated structure only GM ED74 exceeds the theoretical resistance of the column bases. In the case of the non-isolated structure, all GMs exceeded this value. Though, in the case of the GM ED74 the uplift forces, on the isolated structure, are greater than the column base resistance, the values are now closer (of the same order). Thus, an improvement of the column base may solve the problem. The values on the non-isolated structure were impossible to bear with reasonable modifications. As explained above, the uplift forces arise from two sources: the vertical component of the seismic action and the structure overturning due the inertia forces. The base isolation system is capable of mitigate the impact of the latter, but not of the first. In Figure 19 this is demonstrated. In one simulation, the vertical component of the seismic action was considered, and in the other neglected. The simulations were performed on the isolated structure. One can observe that when the vertical component of the seismic action is removed, the uplift loads are barely inexistent. It also clear that the base isolation system manages to eliminate almost $2000 \mathrm{kN}$ of uplift load showing clearly its efficiency. On the other hand, it must be noted that the vertical component of the seismic action is real and cannot be neglected. Therefore, together with the base isolation system, an auxiliary system has to be considered to transfer these forces. 


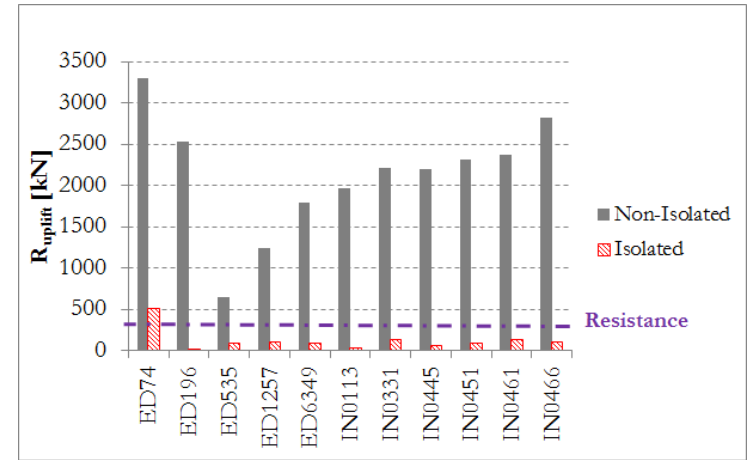

Figure 18: Maximum uplift loads on column bases (all GMs) and theoretical resistance

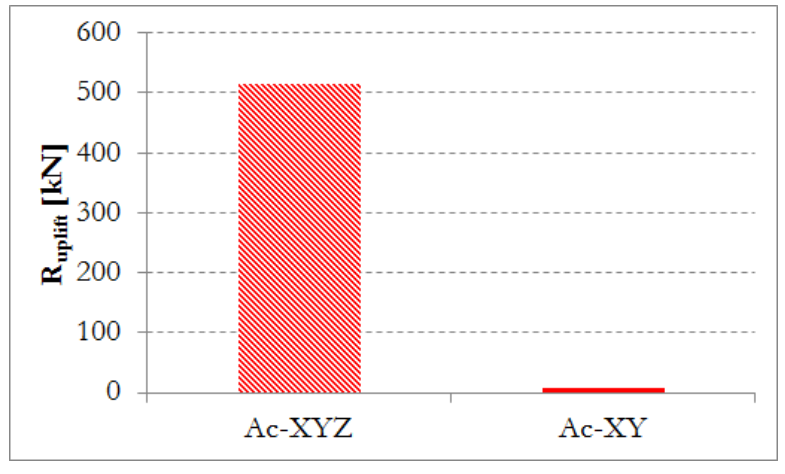

Figure 19: Effect of the vertical component of the seismic action (GM ED74)

\subsection{Performance of the base isolation system}

In order to evaluate the isolators performance demands, the results of the numerical simulations, on the elements of reproducing the devices behavior, are herein discussed. In Figure 20 are shown the force-deformation curves obtained for two GMs. Remember that the deformation represents the distance between the superstructure base and the foundation. This has to be accomplished through movement of the slider on bottom and upper sliding surfaces. The force represents the inertia forces developed in the superstructure which have to be transferred to the supports through the isolators. The two GMs shown represent the extreme cases: the one with smaller deformations and the one with higher deformations. The values measured are considerably different. In the case of GM ED196 the maximum deformation is approximately $125 \mathrm{~mm}$, while in the case of ED1257, the maximum is of approximately $1500 \mathrm{~mm}$. If in the first, the value is perfectly within the deformation capacity of the isolator, the second overcomes this limit excessively. The reason for such differences is on the fundamental period of the base isolation system and on the period at which the ground displacement spectrum attains its maximum. As it can be seen in Figure 21, the latter occurs at approximately 3,5s which corresponds to the fundamental period of the isolators. Thus, a calibration of the isolator properties is required in order to have an isolator that can also perform in the case of seismic actions as GM ED1257. This issue is under investigation at the current stage.

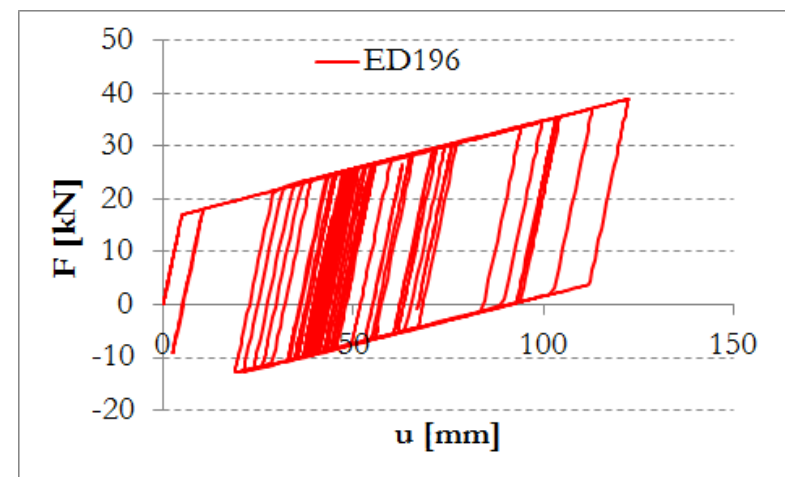

a) ED196

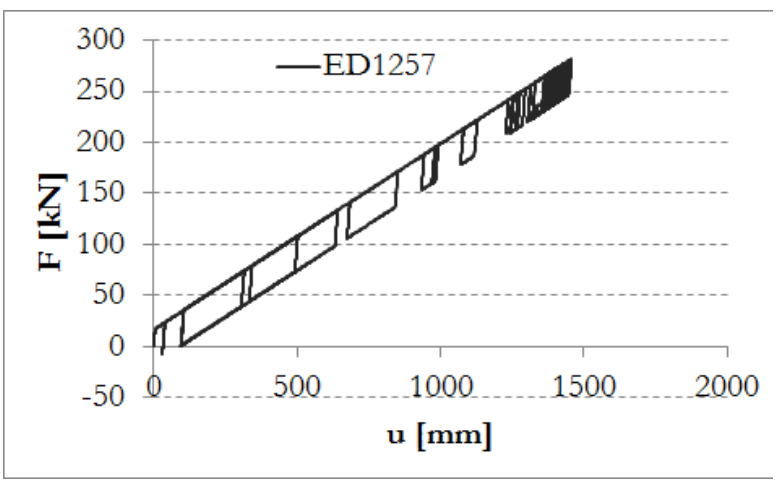

b) ED1257

Figure 20: Force-deformation curve on isolators 


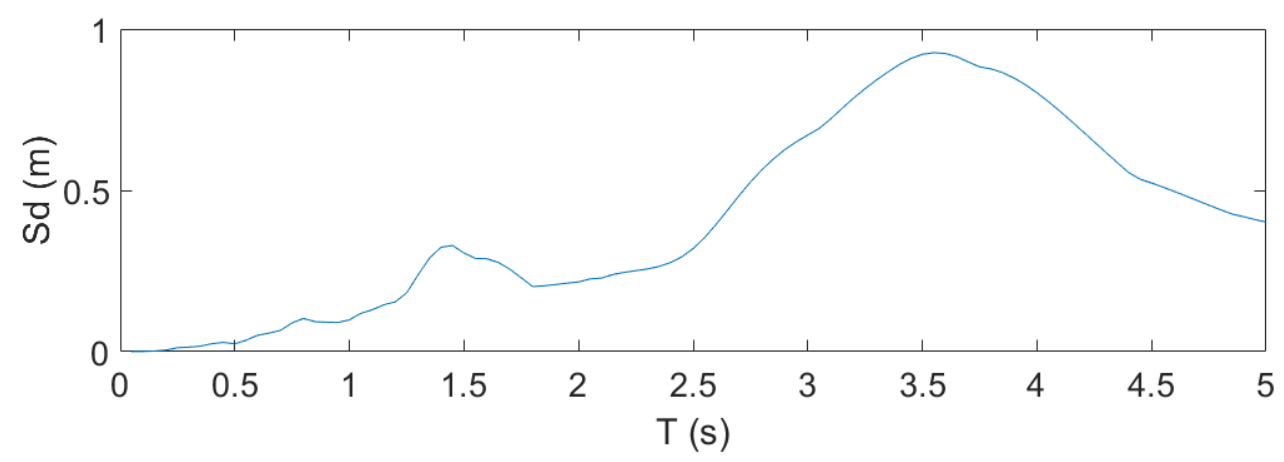

Figure 21: Ground displacement spectrum for GM ED1257 in the X direction (in soil plane)

Figure 20 shows that several cycles are accomplished. A quantification of the number was performed and is shown in Figure 22. The chart presents the number of cycles for different ranges of cycles amplitude. Intervals of $50 \mathrm{~mm}$ of amplitude were defined. In the chart are included all GMs representative of the high seismicity areas. The following observations highlight from these results: i) the majority of the cycles have a small amplitude; ii) only for few GMs high amplitude of cycles occur; iii) the maximum amplitude of the cycles is smaller than the maximum displacement shown in Figure 20-b) for GM ED1257. The latter shows that cycles may occur with minimum deformations of the isolators greater than zero (considerably in some cases). In Figure 23 are quantified the total number of cycles the isolators undergo, independently of the cycles amplitude. The maximum number is 35 and this occurs for the GM ED1257. The minimum is 7 for ED6349.

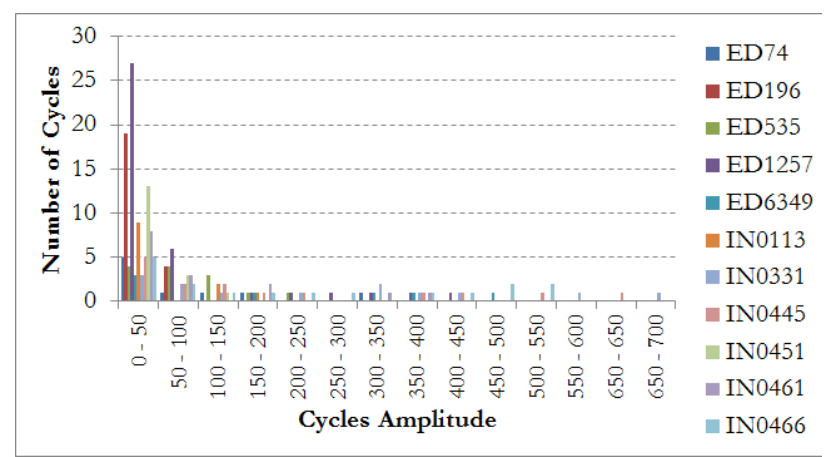

Figure 22: Isolator number of cycles for different cycles amplitude (all GMs)

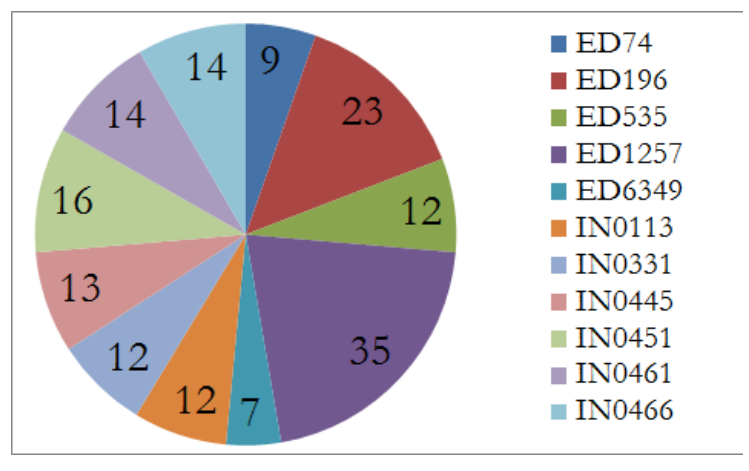

Figure 23: Total number of cycles on isolator (all GMs)

\section{CONCLUSIONS}

This paper presented the work in progress within the RFCS research project PROINDUSTRY dedicated to the seismic protection of industrial plants. In particular, a case study of a gas tank was discussed. The behavior of the tank structure was characterized based on several numerical simulations considering: modal, push-over and time-history nonlinear analysis (in an incremental dynamic analysis procedure). From the latter, the column bases resistance to uplift loads have been identified has the critical part of the structure. Subsequently, the investigation considered the implementation a base isolation system to provide seismic protection to the structure. The base isolation system considered is the double curved surface slider (CSS). From the numerical simulations, on the isolated structure, has been observed that the seismic impact on the structure is mitigated using this device. However, for some ground motions, the deformation 
required on the isolation system, to dissipate the seismic energy, is excessive. This happens because, for some ground motions, the fundamental period of the seismic device is very close to the peak ground response spectrum. Consequently, a calibration of the base isolation system is under investigation.

\section{ACKNOWLEDGEMENTS}

The research leading to these results has received funding from the European Union's Research Fund for Coal and Steel (RFCS) research programme under grant agreement $n^{\circ}$ [RFSR-CT2013-00019].

\section{REFERENCES}

[1] G. Antonioni, S. Bonvicini, G. Spadoni, V. Cozzani, Development of a Frame-work for the Risk Assessment of Na-Tech Accidental Events, Reliability Engineering \& System Safety 94 (9), 1442-50, 2009.

[2] Minitère de l'écologie, du développement durable et de l'énergie, Panorama Des Accidents Industriels Survenus Lors Du Grand Séisme et Tsunami Du Tohoku, Minis-tère de l'écologie, du développement durable et de l'energie, 2013.

[3] W. Salvatore, E. De Pasquale, H. Degee, B. Hoffmeister, C. Castiglioni, F. Braga, C. Butz, Seismic protection of industrial plants by enhanced steel based systems, Annual Re-port - Technical report No 1, project No RFSR-CT-2013-00019, European commission, Brussels, 2013.

[4] W. Salvatore, E. De Pasquale, H. Degee, B. Hoffmeister, C. Castiglioni, F. Braga, C. Butz, Seismic protection of industrial plants by enhanced steel based systems, Mid-Term Report, project No RFSR-CT-2013-00019, European commission, Brussels, 2015.

[5] V.A. Zayas, S.A. Low, S.A. Mahin, The FPS Earthquake Resisting System, Experi-mental Report, Report UCB/EER 87/10, Earthquake Engineering Research Center, University of California, Berkeley, 1987.

[6] European Committee for Standardization, CEN, EN 1993-1-8. Eurocode 3: Design of steel structures. Part 1-8: Design of joints, Brussels, 2005.

[7] European Committee for Standardization, CEN, CEN/TS 1992-4: Design of fastenings for use in concrete, Brussels, 2009.

[8] European Committee for Standardization, CEN, EN 1993-1-6. Eurocode 3: Design of steel structures. Part 1-6: Strength and stability of shell structures, Brussels, 2007.

[9] European Convention for Constructional Steelwork, ECCS, Buckling of steel shells European design recommendations, Publication $\mathrm{n}^{\mathrm{o}}$ 125. John Michael Rotter and Hebert Schmidt (Eds), 5th Edition, September 2013. 